\title{
Compliance With Universal Precautions: Knowledge and Behavior of Residents and Students in a Department of Obstetrics and Gynecology
}

\author{
A.W. Helfgott, ${ }^{1 *}$ J. Taylor-Burton, ${ }^{2}$ F.J. Garcini, ${ }^{1}$ N.L. Eriksen, ${ }^{1}$ and \\ R. Grimes ${ }^{2}$ \\ ${ }^{1}$ University of Texas Health Science Center at Houston, Department of Obstetrics, Gynecology and \\ Reproductive Sciences, Lyndon Baines Johnson Hospital, Houston, TX \\ ${ }^{2}$ University of Texas Health Science Center at Houston, School of Public Health, Houston, TX
}

\begin{abstract}
Objectives: To assess the knowledge of universal precautions for the delivery and operating rooms by residents and students and to evaluate their use of universal precautions.

Study Design: Obstetrics and gynecology $(o b / g y n)$ residents $(\mathrm{n}=30)$ and students $(\mathrm{n}=31)$ from an inner-city, teaching hospital were polled by anonymous questionnaire to assess their knowledge of the appropriate barrier equipment for certain ob/gyn procedures. To determine actual compliance with universal precautions, $459 \mathrm{ob} / \mathrm{gyn}$ procedures were observed. We noted the use of appropriate barrier equipment for each procedure: gloves for pelvic exam and face shields, gowns, gloves, and booties for vaginal delivery, cesarean delivery, and dilation and curettage. The True Epistat statistical software program was used to perform simple regression analysis.

Results: Thirty residents (100\%) knew the appropriate barrier equipment required for each type of procedure performed. One student $(<1 \%)$ did not know that booties were appropriate for the surgical procedures. Rationale for lack of compliance with universal precautions elicited by the questionnaire included time constraints $(64 \%)$, inconvenience $(52 \%)$, and presumption that patient was not infected $(34 \%)$.

The observed rate of compliance with universal precautions by participants indicates that individual compliance was inversely related to the years of experience (overall compliance rate of students was $96 \%$; for first-year residents, $92 \%$, second-year residents, $89 \%$, third-year residents, $84 \%$, fourth-year residents, $78 \% ; r=-0.9918, P=0.0009)$.

Conclusions: Knowledge regarding universal precautions was nearly $100 \%$, while overall observed compliance was only $89 \%$. Compliance with universal precautions was better among students $(96 \%)$ than among residents $(88 \%)$. Compliance with universal precautions was inversely related to years of experience. Infect. Dis. Obstet. Gynecol. 6:123-128, 1998.
\end{abstract}

(C) 1998 Wiley-Liss, Inc.

KEY WORDS

universal precautions; compliance; blood-borne pathogens

Presented at the 20th Annual Meeting of the Infectious Disease Society for Obstetrics and Gynecology. Las Croabas, Puerto Rico. August 5-9, 1997.

*Correspondence to: Dr. Andrew W. Helfgott, Department of OB-GYN-Pensacola, University of Florida College of Medicine, 5045 Carpenter Creek, Pensacola, FL 32513. 
$B^{\mathrm{c}}$ cause of the nature of their work, health care providers in the area of obstetrics and gynecology are faced daily with potential exposure to patients' body fluids (including blood, urine, and amniotic fluid). Exposure may also come in the way of percutaneous injury from contaminated needles and sharp instruments that abound in labor and delivery rooms and surgical suites. As a result of these exposures, health care providers are at increased risk of exposure to blood-borne pathogens, including hepatitis B virus (HBV), hepatitis C virus (HCV), and human immunodeficiency virus (HIV). ${ }^{1-3}$

It has been estimated that $30 \%$ of individuals with percutaneous exposure to $\mathrm{HBV}$ will become infected in the absence of vaccination or prophylaxis if the source is HBeAg positive. ${ }^{4}$ Estimates of the infectivity of health care workers exposed to HBV range from $2-40 \%$ and depend on the titer of virions present in the contaminated blood. ${ }^{5-7}$ Establishing the risk of infection with $\mathrm{HCV}$ after occupational exposure is more difficult, as the estimates of prevalence in the general population are not very reliable. The reported risk for infection with $\mathrm{HCV}$ after an occupational exposure varies from $0-10 \%$ depending on the methodology used for testing. ${ }^{8-10}$ Investigators using polymerase chain reaction to measure $\mathrm{HCV}$ infection by detection of HCV RNA reported an incidence of $10 \% .^{10}$ In the case of HIV, it is estimated that the risk of obtaining HIV from a percutaneous exposure in the health care setting is approximately $0.3 \% .{ }^{3}$ The seroprevalence of HIV in this country has been recently estimated to be $0.3 \% .{ }^{11}$ Although the risk of transmission is smaller than that of $\mathrm{HBV}$ and HCV, the uniformly devastating consequences of HIV infection make it a serious health threat.

The Centers for Disease Control and Prevention (CDC) have published specific universal precautions guidelines that address the issue of prevention of occupational exposure to blood-borne pathogens. These guidelines include recommendations for appropriate protective garments and barrier equipment, proper handling of sharps, and the vaccination of all at-risk health care workers. These recommendations introduce the concept that "all patients should be assumed to be infected with HIV and other blood-borne pathogens." 12

Given the risks of acquiring diseases from blood-borne pathogens, it would be reasonable to expect that health care providers working in the environment of a labor and delivery suite would take precautions against such exposures very seriously. However, recent studies have shown that compliance with universal barrier precautions in the high-risk setting of emergency rooms, surgical suites, and critical care units is less than optimal. ${ }^{13-19}$ Compliance with universal precautions thus becomes an important issue, and determining the reasons for failure to comply with universal precautions becomes an important priority as well.

The purpose of this study was to determine whether obstetric and gynecology residents and medical students are knowledgeable concerning universal precautions and to assess whether they follow these precautions in their daily duties in the labor and delivery rooms and surgical suites of a teaching hospital. The study also examines possible reasons that lead to lapses in the use of universal precautions.

\section{MATERIALS AND METHODS}

Residents from the University of Texas Health Science Center at Houston, Department of Obstetrics, Gynecology and Reproductive Sciences, rotating transitional interns and family medicine residents, as well as medical students rotating on obstetric/ gynecology service, were asked to participate in a two-part study.

The participants were first given a five-part questionnaire to assess their knowledge regarding the use of universal (barrier) precautions for specific obstetric and surgical procedures. Participants were questioned on their knowledge of the potential risk of transmission of blood-borne pathogens such as HBV and HIV by occupational exposure. Finally, participants were asked to rate (as important or not important) what they perceived were reasons for health care workers failing to comply with universal precautions.

In the second part of the study, participants were observed while performing procedures in the labor and delivery and surgical suites. The participants were monitored by the study authors for the use of appropriate universal barrier precautions (specifically the use of gloves, eye protection, gowns, and shoe covers). Criteria for appropriate universal barrier protection to be followed for specific procedures were those dictated by the labor and delivery universal precaution guidelines in ac- 
TABLE I. Barrier devices for specific procedures as recommended by hospital infection control guidelines

\begin{tabular}{lcccc}
\hline Procedure & Gloves & $\begin{array}{c}\text { Eye } \\
\text { protection }\end{array}$ & $\begin{array}{c}\text { Gown } \\
\text { Shoe } \\
\text { covers }\end{array}$ \\
\hline Pelvic exam & $\mathrm{X}$ & & & \\
Amniotomy & $\mathrm{X}$ & $\mathrm{X}$ & $\mathrm{X}$ & \\
Vaginal delivery & $\mathrm{X}$ & $\mathrm{X}$ & $\mathrm{X}$ & $\mathrm{X}$ \\
Cesarean delivery & $\mathrm{X}$ & $\mathrm{X}$ & $\mathrm{X}$ & $\mathrm{X}$ \\
Tubal ligation & $\mathrm{X}$ & $\mathrm{X}$ & $\mathrm{X}$ & \\
Gynecologic & & & & \\
$\quad$ surgery & $\mathrm{X}$ & $\mathrm{X}$ & $\mathrm{X}$ & $\mathrm{X}$ \\
\hline
\end{tabular}

cordance with hospital infection control recommendations (Table 1). Procedures randomly observed were pelvic exams, vaginal deliveries, and surgical procedures (cesarean deliveries, tubal ligations, and dilation and curettages). The level of training, type of procedure performed, and compliance with universal precautions were recorded for each participant involved in an observed event using a standardized report form. Permission for this study was obtained from Committee for the Protection of Human Subjects of the Medical School and the School of Public Health.

The observations were made over a threemonth period (August through October, 1995). Data were collected and analyzed using the Microsoft Access database (Microsoft Corporation, Seattle, WA). Statistical analysis by simple regression analysis was performed using the True Epistat statistical program (Epistat Services, Richardson, TX).

\section{RESULTS}

The anonymous questionnaire was administered to a total of 61 participants: 30 residents and 31 medical students. The participants consisted of 20 residents doing post-graduate training in obstetrics and gynecology (post-graduate years $1-4,5$ residents from each year) plus 10 transitional and family medicine rotating interns. Twenty-eight third-year medical students performing their required clinical clerkship and three fourth-year medical students performing a sub-internship elective participated as well.

An attempt was made to ascertain the participants' knowledge of the risk of transmission of HBV from exposure to an infected patient via a needle stick. Only fourteen participants (23\%) cor- rectly identified the risk of acquiring $\mathrm{HBV}$ from such an exposure. The commonly accepted risk is $30 \% .{ }^{4}$ The majority $(\mathrm{n}=33,54 \%)$ thought that the risk of transmission was $5 \%$ (Table 2).

The same question was asked regarding potential transmission of HIV from exposure to an HIVinfected patient via a needle stick. Fifty four participants $(89 \%)$ correctly identified the published estimated risk of acquiring HIV from such an exposure. The commonly accepted risk is less than 1 in $300\left(0.30 \%\right.$ ) ('Table 2). ${ }^{3}$

The questionnaire next examined the participants' knowledge of guidelines for the use of universal barrier protection as recommended by the CDC. Participants selected the appropriate barrier devices (gloves, gown, eye protection, and shoe covers) to be used for specific procedures. The recommended guidelines for these procedures are depicted in Table 1. For all cases the participants correctly identified the protective barriers recommended and, in some instances, suggested the use of barrier methods over and beyond recommended guidelines (e.g., the use of shoe covers for amniotomy).

The next portion of the questionnaire examined the perception of the participants regarding reasons for lapses in universal barrier precaution use ('Table 3). The study participants were asked to identify reasons they thought health care workers did not comply with universal precautions. Sixty-four percent of the participants identified time constraints as the major reason for not complying with universal precautions $(n=39)$. The next most common reason thought to account for a lack of compliance with universal precautions was that they were "too much trouble" $(\mathrm{n}=32,52 \%)$.

Another reason for lack of compliance was that the respondents thought that perhaps the health care workers could identify whether or not a patient was infected $(n=21,34 \%)$. None of the participants thought that cost was a reason for health care workers not complying with universal precautions.

After the questionnaires were collected, the participants were then observed participating in the various obstetrical and surgical procedures previously described. A total of 459 observations were performed and recorded. Overall, the compliance rate for all the procedures observed was $89 \%$. A closer look at this data shows that the highest com- 
TABLE 2. Number of participants (residents and students) identifying the risk of transmission of hepatitis B and human immunodeficiency virus (HIV) by needle-stick*

\begin{tabular}{|c|c|c|c|c|c|c|c|c|}
\hline & \multicolumn{4}{|c|}{ Risk of hepatitis B transmission } & \multicolumn{4}{|c|}{ Risk of HIV transmission } \\
\hline & $<1 \%$ & $5 \%$ & $30 \% *$ & $100 \%$ & $<1 \% *$ & $5 \%$ & $30 \%$ & $100 \%$ \\
\hline Residents & 7 & 18 & 5 & 0 & 24 & 5 & 1 & 0 \\
\hline Students & 6 & 15 & 9 & 1 & 30 & I & 0 & 0 \\
\hline
\end{tabular}

*Correct answer.

TABLE 3. Reasons study participants felt health care workers do not comply with universal precautions

\begin{tabular}{ll}
\hline Time constraints & $(n=39), 64 \%$ \\
Too much trouble & $(n=32), 52 \%$ \\
Judged patient as not infected & $(n=21), 34 \%$ \\
Do not consider themselves at risk & $(n=14), 23 \%$ \\
Ignorance & $(n=9), 15 \%$ \\
Concerns about cost & $(n=0), 0 \%$ \\
\hline
\end{tabular}

pliance with universal precautions occurred with pelvic exams (100\%), followed by surgical procedures $(89 \%)$ and vaginal deliveries $(83 \%)$. The breakdown of compliance by procedure is described in Table 4. Compliance (by type of barrier device) appeared to be best for the use of latex gloves $(100 \%$ for all procedures). The most commonly neglected barrier was the face shield for eye protection, used in only $67 \%$ of the procedures for which it is recommended.

The data concerning compliance were analyzed with regard to level of training of the participants (Table 5). One hundred observations of medical students revealed an overall compliance rate of $96 \%$. The residents were observed a total of 359 times. Their overall compliance rate was $88 \%$.

When the rate of compliance was analyzed by years of experience it was noted that the compliance rate was highest with interns $(92 \%)$ and lowest with the chief residents $(78 \%)$. Compliance appears to decrease with each additional year of experience: first-year residents complied $92 \%$ of the time, second-year residents, $89 \%$, third-year residents, $84 \%$, and fourth-year residents, $78 \%$. Simple regression analysis of this data reveals that individual compliance was inversely related to the years of experience. This finding was statistically significant $(r=-0.9918, P=0.0009)$.

\section{DISCUSSION}

From the data collected in this study it would appear that the participants had adequate knowledge of the risks of transmission of blood-borne diseases, although their knowledge of risks of transmission for HIV (89\%) was greater than that for HBV (23\%). All the participants were knowledgeable regarding the appropriate universal precautions that must be taken to prevent occupational exposure.

Having sufficient knowledge of how to prevent occupational exposure does not appear to correlate with appropriate compliance with universal precautions. Although not optimal, the overall level of compliance was $89 \%$, which is greater than that observed in similar studies performed in emergency room and operating room settings. ${ }^{14,15,18}$ In a similar study, Kelen et al. showed that strict compliance with universal precautions in emergency room settings occurred in only $44 \%$ of the cases, dropping to $20 \%$ during episodes of profuse bleeding. ${ }^{18}$

The most common reason why the respondents in our study might not have complied with universal precautions was time limitations. Indeed, others have indicated that principle reasons for failure to comply with universal precautions were time constraints and the hindrance of universal precautions in performing a specific task. ${ }^{18}$ It is possible that the Occupational Safety and Health Administration (OSHA) law mandating universal precautions, as well as increasing knowledge about occupationally acquired illnesses, improved the compliance in our study.

Another reason the study participants identified as a possible excuse for not following universal precautions would be the ability of the health care worker to identify patients at high risk for infection. Unfortunately, this has already been shown to be an unreliable method of identifying patients with HIV infection. ${ }^{20}$

It is also noteworthy that the level of compliance was inversely proportional to the level of experience of the participant. Although there is no clear 
TABLE 4. Observed compliance with universal precautions by procedure

\begin{tabular}{|c|c|c|c|c|c|c|}
\hline \multirow[b]{2}{*}{ Procedure } & \multirow[b]{2}{*}{ Observations } & \multicolumn{5}{|c|}{ Universal precautions } \\
\hline & & Gloves & Gown & $\begin{array}{l}\text { Face } \\
\text { shield }\end{array}$ & Booties & $\begin{array}{c}\text { Overall } \\
\text { compliance }\end{array}$ \\
\hline Pelvic exams & 104 & $100 \%$ & NA & NA & NA & $100 \%$ \\
\hline Deliveries & 163 & $100 \%$ & $87 \%$ & $67 \%$ & $79 \%$ & $83 \%$ \\
\hline Surgeries & 192 & $100 \%$ & $98 \%$ & $66 \%$ & $90 \%$ & $89 \%$ \\
\hline Total & 459 & & & & & \\
\hline
\end{tabular}

NA, not applicable.

TABLE 5. Observed compliance with universal precautions by level of training

\begin{tabular}{|c|c|c|c|c|c|c|}
\hline \multirow[b]{2}{*}{ Level of training } & \multirow[b]{2}{*}{ Observations } & \multicolumn{5}{|c|}{ Compliance } \\
\hline & & Overall & Gloves & Gown & Shield & Booties \\
\hline Medical students & 100 & $96 \%$ & $100 \%$ & $99 \%$ & $91 \%$ & $95 \%$ \\
\hline Postgraduate year I & 144 & $92 \%$ & $100 \%$ & $99 \%$ & $76 \%$ & $92 \%$ \\
\hline Postgraduate year 2 & 70 & $89 \%$ & $100 \%$ & $94 \%$ & $80 \%$ & $83 \%$ \\
\hline Postgraduate year 3 & 62 & $84 \%$ & $100 \%$ & $94 \%$ & $80 \%$ & $83 \%$ \\
\hline Postgraduate year 4 & 83 & $78 \%$ & $100 \%$ & $92 \%$ & $53 \%$ & $67 \%$ \\
\hline Total observations & 459 & & & & & \\
\hline
\end{tabular}

reason for this finding, an increasing level of confidence leading to a false feeling of invulnerability or just plain laziness may have contributed to noncompliance with universal precautions.

There are some intrinsic problems with the study itself. Ideally, the participants would have been approached immediately after being observed and questioned as to why they did not comply with universal precautions. This would have given the study authors more information regarding the lack of compliance. However, it was felt that this approach would skew the results, i.e., participants would comply with universal precautions to escape being questioned by the observers. Despite attempts not to influence the participants' compliance with universal precautions, it is possible that the presence of the observer influenced participants' compliance with universal precautions. Participants did see the observers present, although they were not knowledgeable as to why the observers were in the room.

As the risk for exposure and potential infection with disease continues for health care workers, it is essential that they take measures to protect themselves. Despite knowledge regarding the potential for infection and mechanisms to prevent these infections, health care workers are not as compliant with universal precautions as they need to be. Further education regarding universal precautions, stricter observation for compliance, and potential penalties for participants who do not comply will be necessary to bring compliance rates with universal precautions to acceptable levels.

\section{REFERENCES}

1. Short LJ, Bell DM: Risk of occupational infection with blood-borne pathogens in operating and delivery room settings. Am J Infect Control 20:343-350, 1993.

2. Gerberding JL, Bryant-LeBlanc CE, Nelson K, et al.: Risk of transmission of the human immunodeficiency virus, cytomegalovirus, and hepatitis B virus to health care workers exposed to patient with AIDS and AIDSrelated condition. J Infect Dis 156:1-8, 1987.

3. Henderson DK, Fahey BJ, Willy M, et al.: Risk for occupational transmission of human immunodeficiency virus type 1 (HIV-1) associated with clinical exposures: a prospective evaluation. Ann Intern Med 113:740-746, 1990.

4. Seeff LB, Wright EC, Zimmerman HJ, et al.: Type B hepatitis after needle-stick exposure: prevention with hepatitis B immune globulin. Ann Intern Med 88:285293, 1978.

5. Relation of e antigen to infectivity of HbsAg-positive inoculation among medical personnel. Lancet 2:492494, 1976.

6. Alter HJ, Seeff LB, Kaplan PM, et al.: Type B hepatitis: the infectivity of blood exposure for antigen and DNA polymerase after accidental needle-stick exposure. $\mathrm{N}$ Engl J Med 295:909-913, 1976.

7. Werner BG, Grady GF: Accidental hepatitis BB-surfaceantigen-positive inoculation: use of e antigen to estimate infectivity. Ann Intern Med 97:367-369, 1982.

8. Lanphear BP, Linnemann CG, Cannon CG, et al.: Hepatitis $\mathrm{C}$ virus infection in health care workers: risk 
of exposure and infection. Infect Control Hosp Epidemiol 15:745-750, 1994.

9. Zuckerman J, Clewly G, Griffiths P, Cockcroft A: Prevalence of hepatitis $\mathrm{C}$ virus antibodies in clinical healthcare workers. Lancet 343: 1618-1620, 1994.

10. Mitsui T, Iwano K, Masuko K, et al.: Hepatitis $\mathrm{C}$ virus infection in medical personnel after needle stick accident. Hepatol 16: 1109-1114, 1992.

11. Karon JM, Rosenberg PS, McQuillan G, Khare M, Gwinn M, Petersen LR: Prevalence of HIV infection in the United States, 1984 to 1992. JAMA 276:126-131, 1996.

12. Centers for Disease Control. Guidelines,for prevention of transmission of human immunodeficiency virus and hepatitis B virus to health-care and public safety workers. MMWR 38:1-37, 1989.

13. Baraff LJ, Tallinn DA: Compliance with universal precautions in a university hospital emergency department. Ann Emerg Med 18:654-657, 1989.

14. Courington KR, Patterson SL, Howard RJ: Universal precautions are not universally followed. Arch Surg 126: 93-96, 1991.

15. Hammond JF, Eckes JM, Gomez GA, Cunningham $\mathrm{RN}$ : HIV, trauma, and infection control: universal pre- cautions are universally ignored. J Trauma 30:555-561, 1990.

16. Henry K, Campbell S, Maki M: A comparison of observed and self-reported compliance with universal precautions among emergency department personnel at a Minnesota public teaching hospital: implications for assessing infection control programs. Ann Emerg Med 21: 940-946, 1992.

17. Hoffman-Terry M, Rhodes LV, Reed JF: Impact of human immunodeficiency virus on medical and surgical residents. Arch Intern Med 152:1788-1796, 1992.

18. Kelen GD, DiGiovanna TA, Celentano DD, et al.: Adherence to universal (barrier) precautions during interventions on critically ill and injured emergency department patients. J Acquir Immune Defic Syndr Hum Retrovirol 3:987-994, 1990.

19. Goetz A, Yu CM, Muder RR: Entering first-year residents' experiences and knowledge of infection control of hepatitis B and HIV, at five university-affiliated hospitals. Acad Med 67:275-276, 1992.

20. Centers for Disease Control and Prevention. U.S. Public Health Service recommendations for human immunodeficiency virus counseling and voluntary testing for pregnant women. MMWR 44(RR-7):5-6, 1995. 


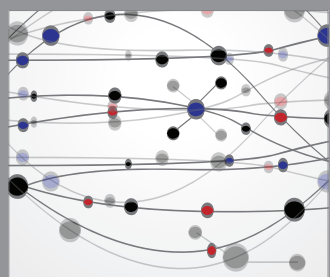

The Scientific World Journal
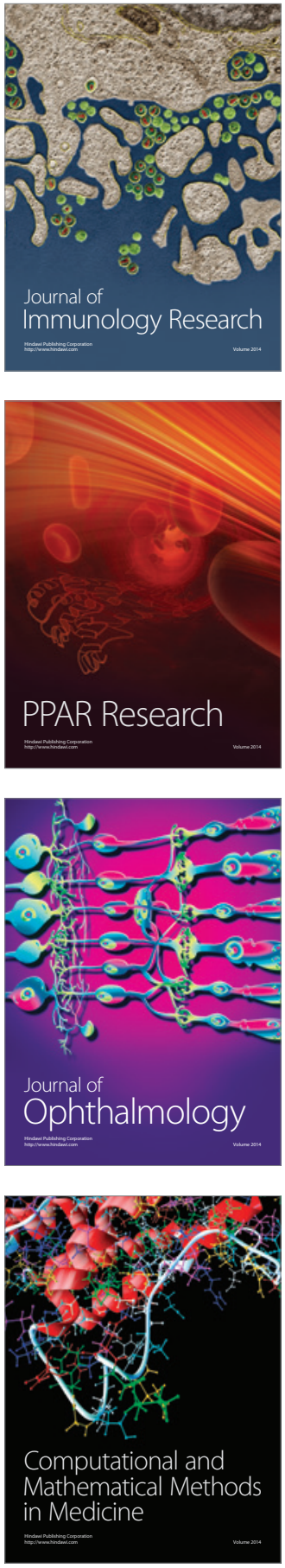

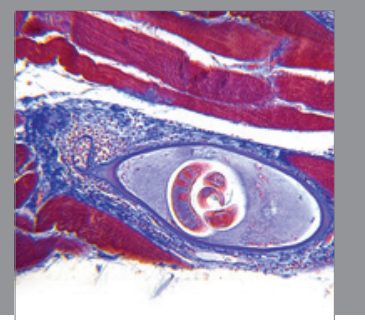

Gastroenterology

Research and Practice
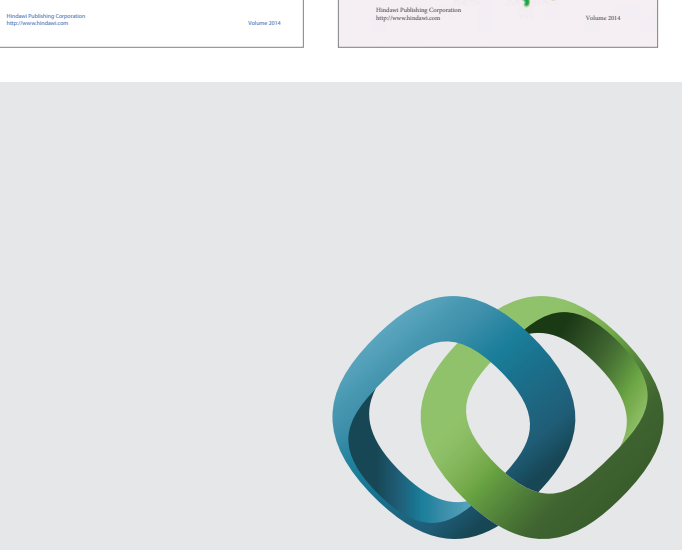

\section{Hindawi}

Submit your manuscripts at

http://www.hindawi.com
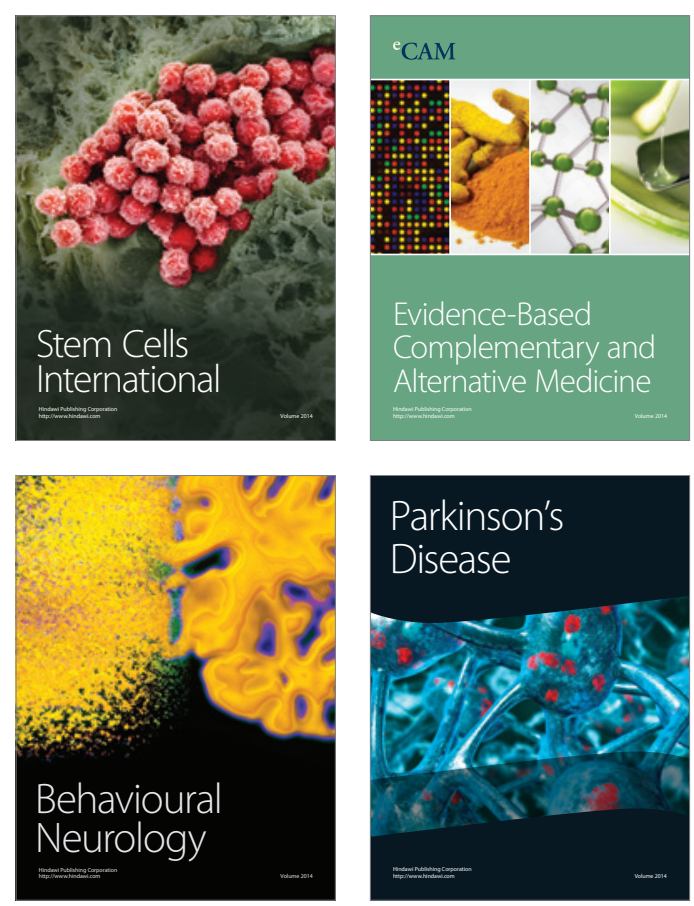

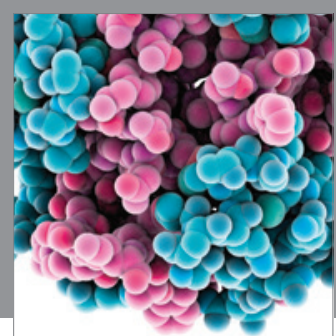

Journal of
Diabetes Research

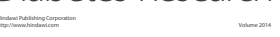

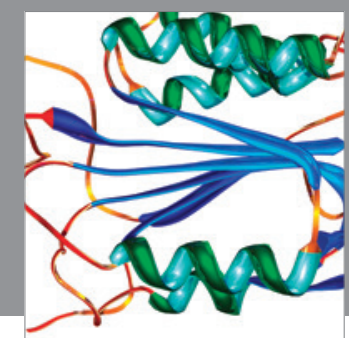

Disease Markers
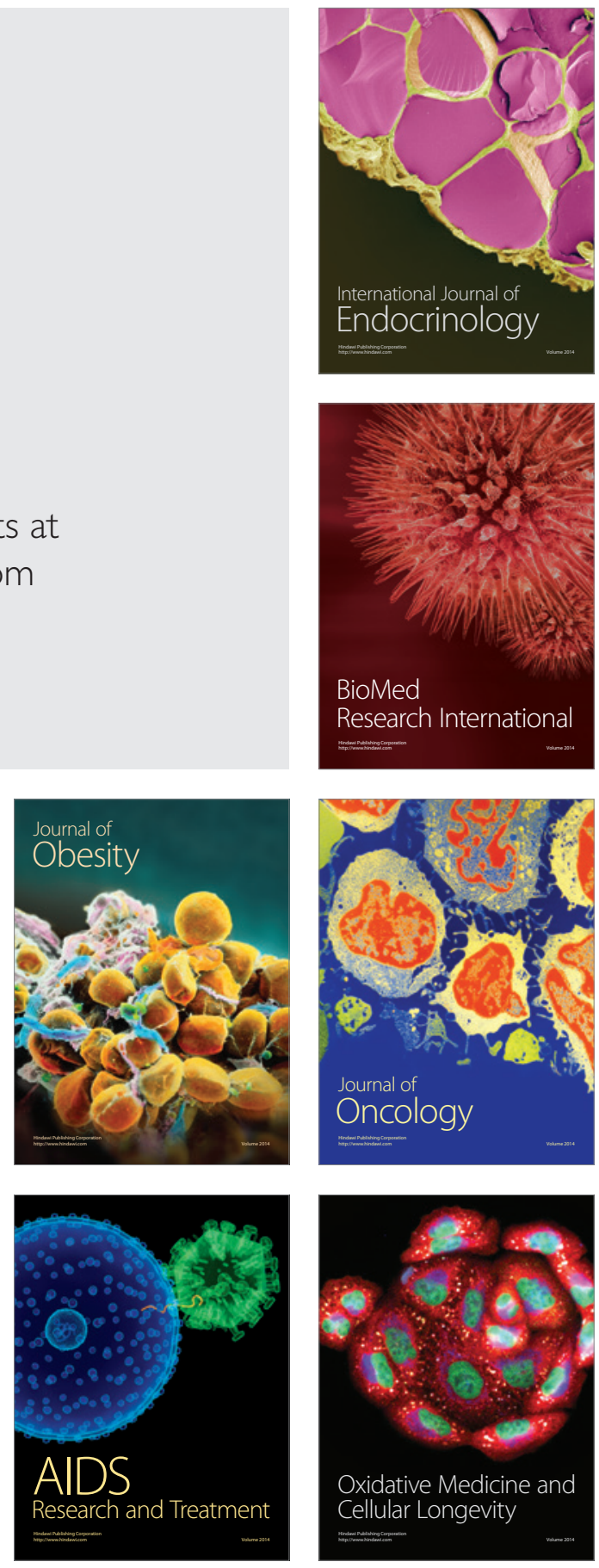